\title{
Atención de las Toxicosis en la Consulta Prenatal
}

Doctores: Gustavo Riaño, Carlos Martínez-Sáenz y Leonor Concha de Vargas

Con miras permanentes a disminuír la incidencia de las toxicosis gravidicas en el Instituto, hemos adoptado en forma rutinaria una estrecha vigilancia de las pacientes exceptuando las deficiencias debidas al grado de cultura y a la mentalidad de la clientela hospitaliaria. Desgraciadamente es difícil llevar esta vigilancia hasta el punto deseado, ya que con frecuencia ocurre la falta de colaboración $e$ interés por parte de la mayoria de las pacientes. Es lamentable tener que reconocer que, a pesar de la larga trayectoria de los servicios de maternidad en Bogotá, aun las mismas pacientes, tratadas en varias oportunidades en el Instituto, menosprecian $\mathrm{y}$ descuidan sus problemas obstétricos $\mathrm{y}$ permanecen sin vigilancia alguna o lo que es peor se entregan a los cuidados de comadronas ignorantes y sólo concurren a la consulta médica cuando se ven enfrentadas a una complicación 0 accidente que las haga temer por su vida. Por otra parte la generalidad de las embarazadas ni siquiera consideran que sea útil acudir al médico en los primeros meses, salvo que sufran alguna complicación que las haga sentirse enfermas.

A toda gestación que llega por primera vez a la consulta se le hace una historia clínica detallada, anotando especialmente los antecedentes cardiorrenales y tóxicos; los resultados del examen clínico general en el que anota toda deficiencia anatómica o funcional; se registran cuidadosamente el peso y la tensión arterial y se ordenan exámenes de orina, serología y fotofloroscopia pulmonar.

En los exámenes posteriores periódicos tan pronto como se aprecia hipertension o edemas se ordena una dieta declorurada hasta cuando se conozcan los resultados de los exámenes de laboratorio. Se instruye a la paciente sobre el peligro que vepresentan. tanto para ella como para su hijo, el incumplimiento a las citas que se le den para que asista a la consulta. Se instituye el tratamiento de la constipación intestinal a base de laxantes y se la instruye sobre los preceptos higiénicos fundamentales.

El mismo cuidado especial se sigue en los casos en que sea el vómito el motivo de la consulta, pues entre el vómito simple, que no repercute sobre la salud de la gestante, y la hipermesis gravídica no hay más que diferencia de grados; en tales casos además del régimen empleamos los sedantes del sistema nervioso, los antihistaminicos y la piridoxina.

A todas estas pacientes se les da cita para que vuelvan a consulta dos dias más tarde, con el fin de revisar el peso y la tensión arterial y conocer el resultado del nuevo análisis de la orina, para instituír el tratamiento adecuado a base de régimer. de clorurado, reducción de líquidos, administración de sulfato de magnesia, y de solución dextrosada hipertónica, reposo y abrigo y se cita para una nueva consulta.

Los casos de preeclampsia, si son muy leves se tratan en forma análoga pero si tienen alguna gravedad, se hospitalizan inmediatamente. 